\title{
Effects of tocotrienol-rich fraction on exercise endurance capacity and oxidative stress in forced swimming rats
}

\author{
Shu-Ping Lee $\cdot$ Guang-Yuan Mar $\cdot$ Lean-Teik Ng
}

Accepted: 4 August 2009 / Published online: 25 August 2009

(C) Springer-Verlag 2009

\begin{abstract}
The present study aimed to examine the effects of tocotrienol-rich fraction (TRF) on exercise endurance and oxidative stress in forced swimming rats. Rats fed on isocaloric diet were orally given 25 (TRF-25) and 50 (TRF50) $\mathrm{mg} / \mathrm{kg}$ of $\mathrm{TRF}$, or $25 \mathrm{mg} / \mathrm{kg} \mathrm{D}$ - $\alpha$-tocopherol (T-25) whilst the control group received only the vehicle for 28 days, followed by being forced to undergo swimming endurance tests, with measurements taken of various biochemical parameters, including blood glucose, lactate and urea nitrogen, glycogen, total antioxidant capacity, antioxidant enzymes, thiobarbituric acid-reactive substances (TBARS), and protein carbonyl. Results showed that the TRF-treated animals $(268.0 \pm 24.1 \mathrm{~min}$ for TRF-25 and $332.5 \pm 24.3 \mathrm{~min}$ for TRF-50) swam significantly longer than the control $(135.5 \pm 32.9 \mathrm{~min})$ and $\mathrm{T}$-25-treated $(154.1 \pm 36.4 \mathrm{~min})$ animals, whereas there was no difference in the performance between the T-25 and control groups. The TRF-treated rats also showed significantly higher concentrations of liver glycogen, superoxide dismutase (SOD), catalase (CAT), and glutathione peroxidase (GPx), as well as of muscle glycogen and SOD than the control and the T-25-treated animals, but lower levels in
\end{abstract}

S.-P. Lee

Ping Tin Enterprise Co., Ltd., Kaohsiung, Taiwan

G.-Y. Mar

Internal Medicine Department,

Kaohsiung Veteran General Hospital, Kaohsiung, Taiwan

L.-T. $\mathrm{Ng}(\bowtie)$

Department of Agricultural Chemistry,

National Taiwan University, No. 1, Sec. 4,

Roosevelt Road, Taipei 106, Taiwan

e-mail: nglt97@ntu.edu.tw blood lactate, plasma and liver TBARS, and liver and muscle protein carbonyl. Taken together, these results suggest that TRF is able to improve the physiological condition and reduce the exercise-induced oxidative stress in forced swimming rats.

Keywords Tocotrienol-rich fraction $\cdot \alpha$-Tocopherol . Exercise endurance $\cdot$ Oxidative stress

\section{Introduction}

Free radical production has been shown to increase significantly after physical activities in human and animal models (Ashton et al. 1998; Bejma and Ji 1999). These free radicals could cause damage to biological molecules in the body (Polidori et al. 2000). Antioxidants are generally believed to protect against exercise-induced oxidative stress and reduce the degree of exhaustion caused by continuous physical activity (Rossi et al. 2000). However, if antioxidant systems become depleted during exercise, cells and tissues are more susceptible to reactive oxygen species (ROS) damage (Chiaradia et al. 1988).

Vitamin $\mathrm{E}$ is composed of eight different forms, four tocopherols ( $\alpha-, \beta-, \gamma-$ and $\delta$-), and four tocotrienols $(\alpha-, \beta-, \gamma-$ and $\delta$-). It is a potent lipid-soluble antioxidant in biological system that has the ability to directly quench free radicals and function as a membrane stabilizer. Studies have shown that vitamin E supplementation protected against exerciseinduced oxidative stress in humans (Meydani et al. 1993; Zoppi et al. 2006) and rats (Kumar et al. 1992; Ciocoiu et al. 2007), as well as improving physical endurance in mice (Novelli et al. 1990). Studies also showed that endurance training can cause the depletion of vitamin $E$ in both liver and skeletal muscle of rats (Aikawa et al. 1984). Its 
depletion can lead to a rapid formation of lipid peroxides in these tissues (Bieri and Anderson 1960; Zoppi et al. 2006). In another study, a significantly higher lipid peroxidation in liver and muscle was noted in rats not receiving vitamin $\mathrm{E}$ supplementation than in rats receiving vitamin E supplementation (Tiidus et al. 1993).

Tocotrienol-rich fraction (TRF), a major bioactive component of palm oil, has been shown to possess potent antioxidant (Serbinova et al. 1991; Maniam et al. 2008), anti-inflammatory (Wu et al. 2008), anticancer (Goh et al. 1994; Takahashi and Loo 2004; Wu and Ng 2007), neuroprotection (Sen et al. 2000; Osakada et al. 2004), and cholesterol-lowering (Qureshi et al. 1995; Minhajuddin et al. 2005) activities. It was also reported to be more potent than $\alpha$-tocopherol against oxidative damage in brain mitochondria (Kamat and Devasagayam 1995), and more effective in inhibiting protein oxidation and lipid peroxidation in liver microsomes (Nesaretnam et al. 1993). However, the effects of TRF on physical exercise have never been investigated. In this study, our aim was to examine the effects of TRF on exercise endurance and exercise-induced oxidative stress in forced swimming rats.

\section{Materials and methods}

A series of experiments were conducted to examine the effects of tocotrienol-rich fraction on exercise endurance and oxidative stress in rats subjected to forced swimming through measurements of antioxidant enzymes, protein and lipid peroxidation, and other biochemical indicators in organs and tissues.

\section{Chemicals}

D- $\alpha$-Tocopherol (T), thiobarbituric acid (TBA), 2,2'-azinobis[3-ethylbenthiaoline-6-sulfonic acid] (ABTS), superoxide dismutase, catalase and glutathione peroxidase were purchased from Sigma Chemical Co. (St. Louis, MO, USA). Anthrone was supplied by Fluka Chemical Co. (Buchs, Switzerland). All other chemicals used were of analytical grade.

\section{Tocotrienol-rich fraction (TRF)}

A mixture containing a full spectrum of palm vitamin $\mathrm{E}$ analogues comprising mainly tocotrienols was supplied by Carotech Ltd. (Malaysia). It consists of $15.38 \%$ $\alpha$-tocotrienol, $28.20 \% \gamma$-tocotrienol, $6.42 \% \delta$-tocotrienol, $15.34 \% \alpha$-tocopherol, $12.82 \%$ plant squalene, $5.12 \%$ phytosterol, and $16.72 \%$ other minor phytonutrients. All experiments were conducted using TRF obtained from the same batch.
Animals

Male Wistar rats, aged 6-weeks, were obtained from the National Laboratory of Animal Breeding and Research Center (Taipei, Taiwan). They were housed in a controlled environment with temperature maintained at $22 \pm 3^{\circ} \mathrm{C}$ and humidity at $55 \pm 5 \%$ under a 12:12 h light/dark cycle. Animals were fed a standard isocaloric chow diet (Fwusow Industry Co. Ltd., Taichung, Taiwan) and tap water ad libitum until use. Food intake was recorded everyday whilst body weight gain was measured every 2 days. All animal experiments were conducted according to the guidelines of the Council of Agriculture, the Executive Yuan of Taiwan, and approved by the National and Institutional Animal Care Committee.

\section{Exercise endurance capacity}

After a week of adaptation to the gavage procedure, animals were randomly divided into four groups, with ten rats per group, and were subjected to the following treatments. Group one was used as a control, which received the vehicle only; group two received $25 \mathrm{mg} / \mathrm{kg} / \mathrm{ml}$ of TRF (TRF-25); group three received $50 \mathrm{mg} / \mathrm{kg} / \mathrm{ml}$ of TRF (TRF-50); and group four received $25 \mathrm{mg} / \mathrm{kg} / \mathrm{ml}$ of $\alpha$-tocopherol (T-25). All animals were subjected to their respective treatments by gavage for 28 days. Soybean oil was used to adjust the caloric content of each treatment. The experiment was conducted as a double blind test.

The swimming endurance capacity was assessed $10 \mathrm{~h}$ after the last treatment according to Abe et al. (1995). The apparatus used in this test was an acrylic plastic pool $(90 \times 60 \times 60 \mathrm{~cm})$ filled with water maintained at $28 \pm 1{ }^{\circ} \mathrm{C}$. The water in the acrylic plastic pool was $40-\mathrm{cm}$ deep. Rats were forced to swim in the water, and the endurance was defined as the time they kept swimming actively until the animal submerged in water without movement.

To diminish stress, all rats had been accustomed to swimming with repeated short-term swimming sessions for a week before experiment. This exercise in familiarization of swimming prior to treatments allowed minimizing the scattering of data and improving the accuracy of data on swimming capacity.

Blood and tissue sample preparation

Immediately before and after exercise, blood was taken from the orbital sinus of the rats under anesthesia for glucose, lactate and urea nitrogen content measurements. At the end of the experiment, blood was obtained under anesthetized condition from the posterior vena cava for lipid peroxide and total antioxidant analyses, whereas the liver and skeletal muscle were removed, weighed, homogenized 
with $10 \mathrm{ml}$ of $150 \mathrm{mM} \mathrm{KCl-Tris-HCl}$ buffer (pH 7.2), followed by centrifuging at $500 \times g$ for $10 \mathrm{~min}$ to give a supernatant of liver or muscle homogenate. With the exception of samples prepared for glycogen measurements, all other homogenates were kept at $-80^{\circ} \mathrm{C}$ until analysis.

Blood glucose, lactate and urea nitrogen (BUN), and antioxidant enzymes analyses

Blood samples were analyzed for glucose, lactate and BUN using commercial kits with ELISA, and conducted according to the manufacturer's procedures (Roche Diagnostic Systems Inc., NJ, USA). Catalase (CAT) activity was determined according to Beers and Sizer (1952) by following the decomposition of $\mathrm{H}_{2} \mathrm{O}_{2}$ at $240 \mathrm{~nm}$ at $25^{\circ} \mathrm{C}$. Superoxide dismutase (SOD) activity was measured spectrophotometrically, as the inhibition of epinephrine spontaneous autooxidation at $480 \mathrm{~nm}$ (Sun and Zigman 1978). Glutathione peroxidase (GPx) was assayed according to the method of Rotruck et al. (1973), and its activity was estimated in terms of glutathione utilization at absorbance $412 \mathrm{~nm}$.

\section{Total antioxidant capacity (TAC)}

The ABTS assay (Re et al. 1999) was employed to measure the TAC in plasma. In brief, ABTS was dissolved in deionised water to $7 \mathrm{mM}$ concentration, which was then mixed with $2.45 \mathrm{mM}$ potassium persulfate. The ABTS radical scavenging activity was determined by mixing with $180 \mu \mathrm{l}$ ABTS reagent and $40 \mu \mathrm{l}$ of sample, followed by measuring at absorbance $734 \mathrm{~nm}$.

\section{Glycogen analysis}

Glycogen was determined by the method as described by Caroll et al. (1956). In short, tissue glycogen was isolated and purified by precipitation with ethanol from a digest formed by the addition of a $300 \mathrm{~g} / 1$ potassium hydroxide solution. Anthrone reagent $(2 \mathrm{ml})$ was then added to $0.1 \mathrm{ml}$ of tissue glycogen or to the standard glycogen solution. After incubating the mixture in boiling water for $10 \mathrm{~min}$, spectrometric measurement was read at $620 \mathrm{~nm}$.

Determination of protein oxidation and lipid peroxidation

The degree of protein oxidation was determined using a protein carbonyl assay kit (Cayman Chemical Co., MI, USA). Lipid peroxidation was ascertained by the formation of malondialdehyde (MDA) and measured by the thiobarbituric acid-reactive method according to Kimura et al. (1981).
Statistical analysis

Data are presented as means \pm standard deviations (SD). Values were evaluated by one-way ANOVA, followed by Duncan's multiple range tests. Differences were considered significant when $P$-value was $<0.05$.

\section{Results}

Effects of TRF and T on the body weight of rats

Results showed that the initial (Day 0) and final (Day 28) body weights of rats were not significantly different between treatments, with the body weight ranging from 295 to $298 \mathrm{~g}$ on day 0 and varying from 351 to $375 \mathrm{~g}$ on day 28 . Similarly, food intakes between the different treatments were also not significantly different.

\section{Swimming endurance test}

Figure 1 shows the swimming times of rats receiving different treatments. Results showed that the TRF-treated groups (TRF-25: $268.0 \pm 24.1 \mathrm{~min}$; TRF-50: $332.5 \pm 24.3 \mathrm{~min}$ ) swam significantly $(P<0.05)$ longer than the control $(135.5 \pm 32.9 \mathrm{~min})$ and $\mathrm{T}-25$-treated $(154.1 \pm 36.4 \mathrm{~min})$ animals. Compared with the control group, the increases in swimming time for TRF-25 and TRF-50 were 97.8 and $145.4 \%$, respectively. Surprisingly, the T-25-treated animals showed only a minimal increase in swimming duration $(26.3 \%)$.

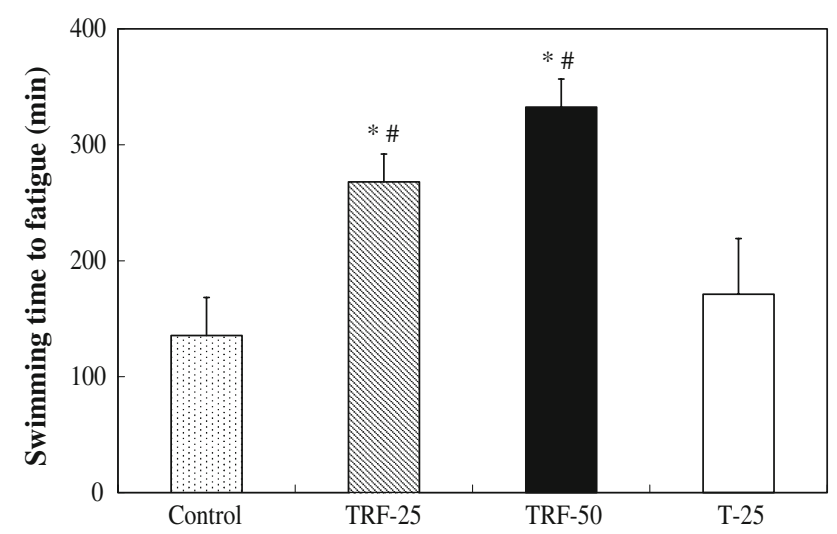

Fig. 1 Effects of tocotrienol-rich fraction (TRF) and $\alpha$-tocopherol (T) on swimming time of rats. Data are presented as mean \pm SD of ten rats per group. *Indicates a significant difference from the control group at $P<0.05$; "Indicates a significant difference from the T-25-treated group at $P<0.05$ (Duncan's multiple range tests) 
Blood glucose, lactate, and urea nitrogen (BUN) concentrations

The measurements of blood glucose, lactate and BUN were conducted before and after swimming, of which the results are shown in Table 1. It was found that the blood glucose concentrations between the different treatments were not significantly different before swimming. However, attenuated decreases in the blood glucose level (control: $-11.59 \%$; TRF-25: $-1.81 \%$; TRF-50: $-2.04 \%$; T-25: $-5.65 \%$ ) were noted for all treatments after swimming.

The concentrations of blood lactate among all groups before swimming were not significantly different $(P>0.05)$, varying between 3.90 and $4.39 \mathrm{mg} / \mathrm{dl}$. However, post-exercise showed significant $(P<0.05)$ higher blood lactate levels in the control $(67.38 \%)$ and T-25 $(109.02 \%)$ groups than in the TRF-25 (49.74\%) and TRF-50 (18.45\%) treated animals. The TRF-treated groups demonstrated an ability to retard and lower the blood lactate produced after exercise.

All treatments showed significant $(P<0.05)$ increases in the BUN level after exercise, with increases of $86.83 \%$, $76.91 \%, 76.09 \%$, and $96.11 \%$ for the control, TRF-25, TRF-50, and T-25, respectively, as compared with the levels before exercise.

\section{Liver glycogen content}

Figure 2 shows the levels of liver and muscle glycogen after exercise. Results showed that the glycogen concentrations in liver and muscle of the control and T-25 treated animals were significantly lower than in the TRF groups. Surprisingly, $\mathrm{T}-25$ exhibited the lowest level of muscle glycogen content.

Thiobarbituric acid-reactive substances (TBARS) concentration

The concentration change in TBARS is the change in metabolic products derived from lipid peroxidation after exercise. Figure 3 shows the levels of TBARS in plasma, liver,
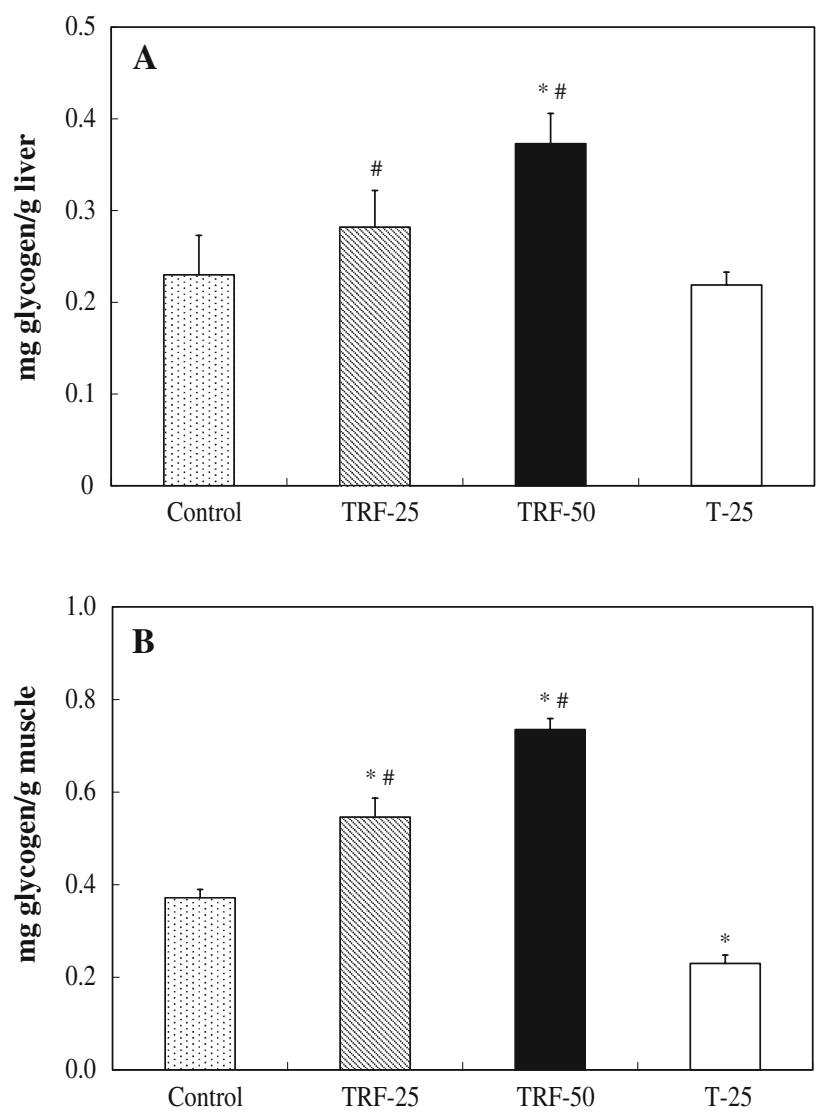

Fig. 2 Concentrations of glycogen after maximal swimming exercise in different tissues. a Liver and $\mathbf{b}$ muscle. Data are presented as mean \pm SD of ten rats per group. *Indicates a significant difference from the control group at $P<0.05 ;$ " Indicates a significant difference from the T-25-treated group at $P<0.05$ (Duncan's multiple range tests)

and muscle of rats in different groups. After exercise, the levels of TBARS in plasma and liver of the TRF- and T-treated animals were significantly lower $(P<0.05)$ than in the control group, with the TRF-50-treated group exhibiting the lowest TBARS level. However, there was no difference between treatments in the muscle TBARS level.

Table 1 Effects of tocotrienol-rich fraction (TRF) and $\alpha$-tocopherol (T) on blood glucose, lactate and urea nitrogen (BUN) concentrations in forced swimming rats

\begin{tabular}{|c|c|c|c|c|c|c|}
\hline \multirow[t]{2}{*}{ Treatments } & \multicolumn{2}{|l|}{ Glucose $(\mathrm{mg} / \mathrm{dl})$} & \multicolumn{2}{|l|}{ Lactate $(\mathrm{mg} / \mathrm{dl})$} & \multicolumn{2}{|l|}{ BUN (mg/dl) } \\
\hline & Before exercise & After exercise & Before exercise & After exercise & Before exercise & After exercise \\
\hline Control & $110.00 \pm 13.66$ & $97.25 \pm 9.92$ & $4.94 \pm 1.04$ & $7.08 \pm 0.94$ & $18.15 \pm 2.79$ & $33.91 \pm 4.05$ \\
\hline TRF-25 & $105.10 \pm 9.35$ & $103.20 \pm 7.98$ & $3.90 \pm 0.29$ & $5.84 \pm 0.92^{\#}$ & $18.45 \pm 2.30$ & $32.64 \pm 2.83$ \\
\hline TRF-50 & $117.90 \pm 24.16$ & $115.50 \pm 10.11$ & $4.39 \pm 0.71$ & $5.20 \pm 0.54^{* \#}$ & $18.95 \pm 2.54$ & $33.37 \pm 1.30$ \\
\hline $\mathrm{T}-25$ & $101.90 \pm 17.03$ & $96.14 \pm 3.21$ & $4.10 \pm 0.73$ & $8.57 \pm 1.65$ & $17.75 \pm 2.45$ & $34.81 \pm 2.23$ \\
\hline
\end{tabular}

Data are presented as mean $\pm \mathrm{SD}$ of 10 rats per group

* A significant difference from the control group at $P<0.05$

\# A significant difference from the T-25-treated group at $P<0.05$ (Duncan's multiple range tests) 

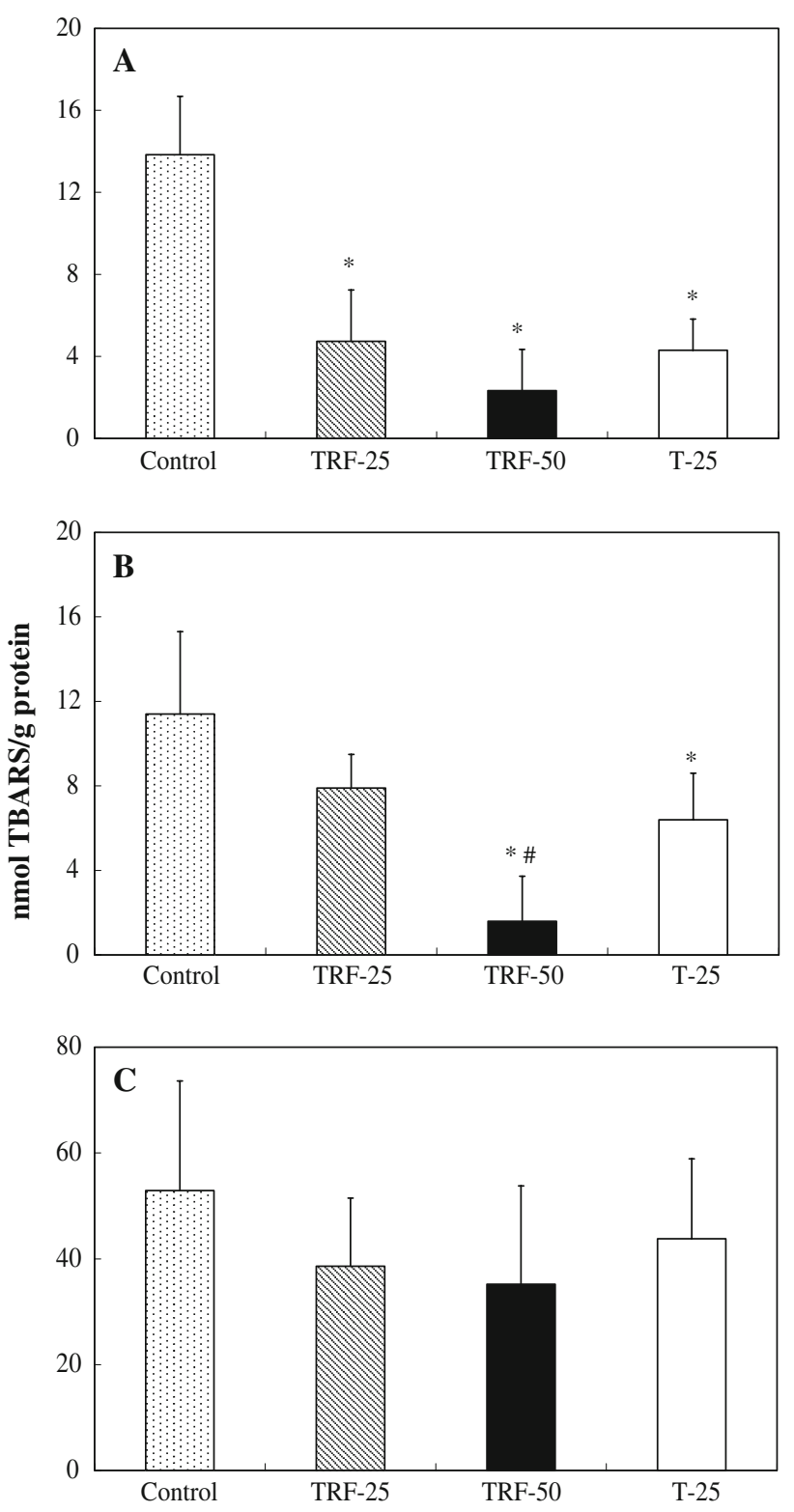

Fig. 3 Concentrations of thiobarbituric acid-reactive substances (TBARS) after maximal swimming exercise in different tissues. a Plasma; b liver and c muscle. Data are presented as mean $\pm \mathrm{SD}$ of ten rats per group. *Indicates a significant difference from the control group at $P<0.05$; "Indicates a significant difference from the T-25-treated group at $P<0.05$ (Duncan's multiple range tests)

\section{Protein carbonyl content}

Figure 4 shows the protein carbonyl concentrations in liver and muscle of the different treatments. Both the TRF- and T-treated animals tended to have lower levels of protein carbonyl in the liver. The level in muscle was found to remain high after the T-25 treatment. The protein carbonyl levels in liver and muscle of the control and T-25 groups were significantly higher $(P<0.05)$ than in the TRF-50 treated animals.

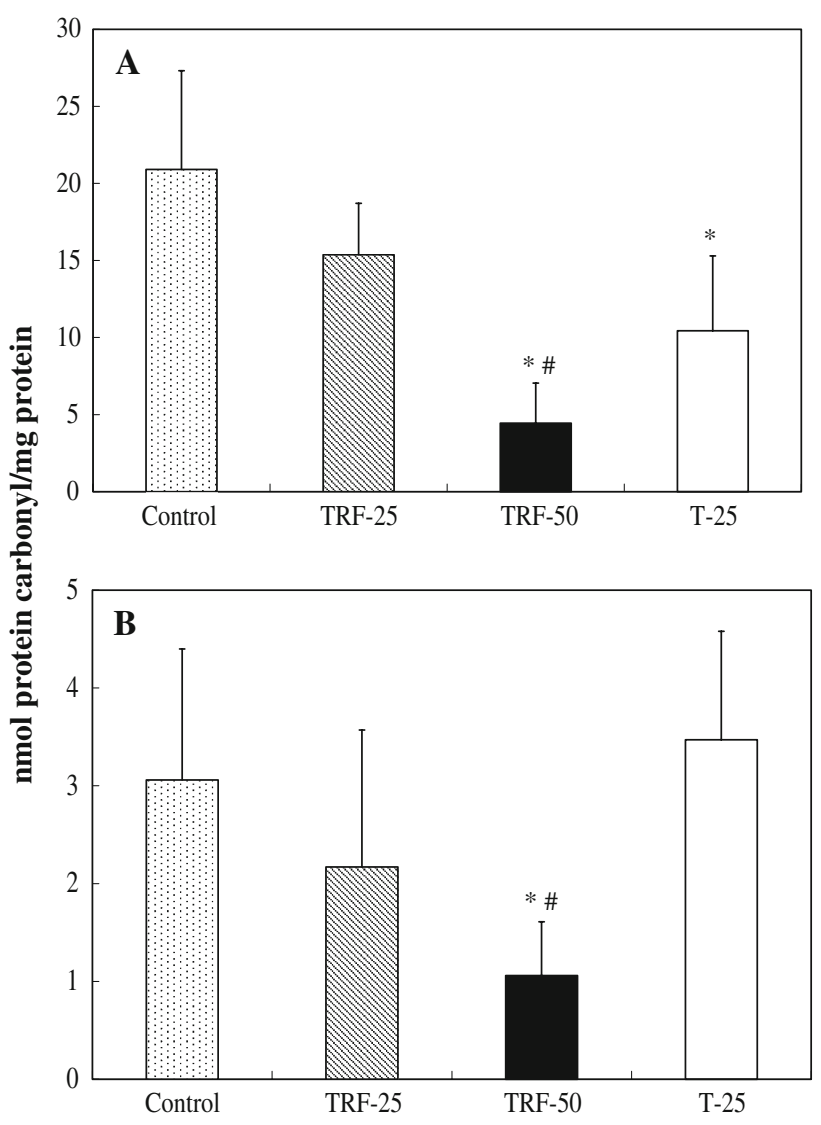

Fig. 4 Concentrations of protein carbonyl after maximal swimming exercise in different tissues. a Liver and $\mathbf{b}$ muscle. Data are presented as mean $\pm \mathrm{SD}$ of ten rats per group. *Indicates a significant difference from the control group at $P<0.05$; Indicates a significant difference from the T-25-treated group at $P<0.05$ (Duncan's multiple range tests)

Total antioxidant capacity (TAC)

To examine whether the supplementation of TRF and T did lead to an increased level of antioxidants in the plasma, TAC was measured by ABTS assay. Compared with the control group, results showed that only TRF-50 administration led to a significant $(P<0.05)$ increase in the plasma TAC level (Fig. 5).

Antioxidant enzymes

Figures 6, 7 and 8 show the levels of SOD, CAT and GPX in liver and muscle of animals receiving different treatments. Compared with the control group, the TRF-50 treatment showed significant increases in liver and muscle SOD, liver CAT and GPx levels. The muscle SOD, and liver CAT and GPx concentrations of the TRF-treated animals were significantly $(P<0.05)$ higher than in the T-25 group. However, there was no difference in muscle CAT and GPx 


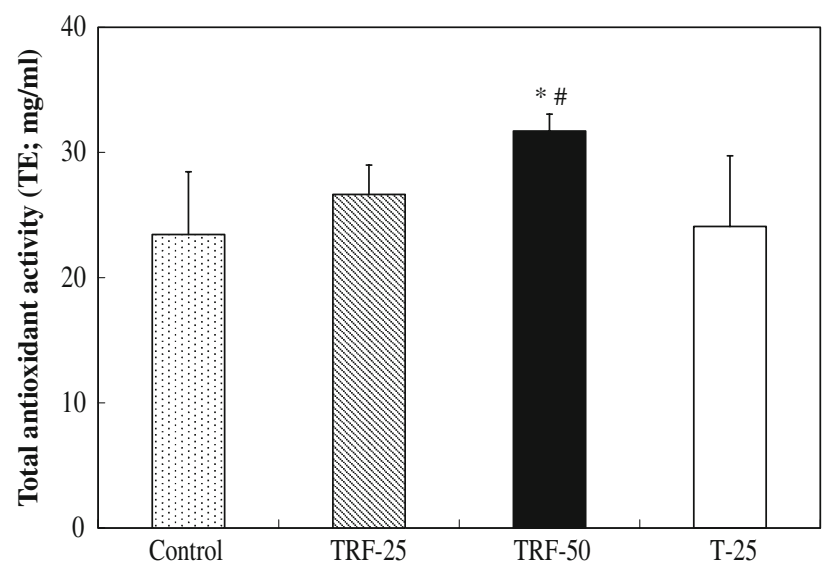

Fig. 5 Total antioxidant activity (Trolox equivalent) after maximal swimming exercise in plasma. Data are presented as mean $\pm \mathrm{SD}$ of ten rats per group. *Indicates a significant difference from the control group at $P<0.05$; "Indicates a significant difference from the T-25treated group at $P<0.05$ (Duncan's multiple range tests)

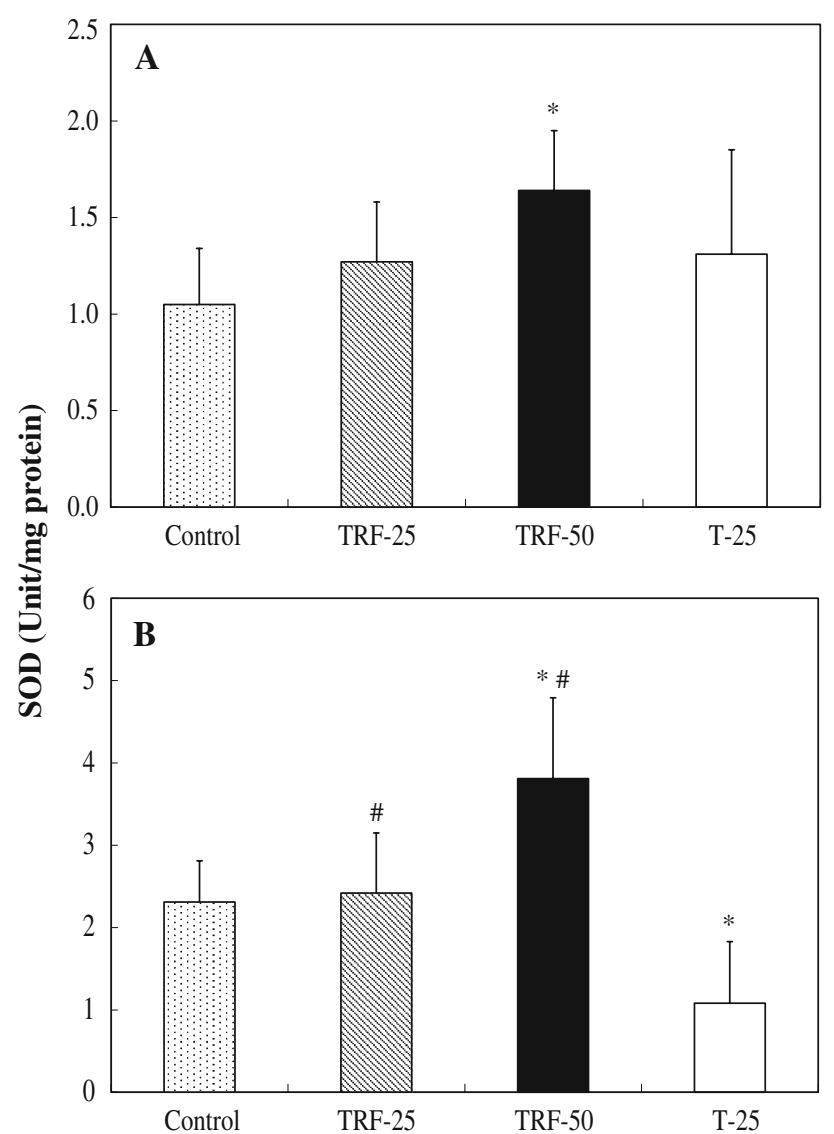

Fig. 6 Concentrations of superoxide dismuatse (SOD) after maximal swimming exercise in different tissues. a Liver and $\mathbf{b}$ muscle. Data are presented as mean $\pm \mathrm{SD}$ of ten rats per group. *Indicates a significant difference from the control group at $P<0.05$; ${ }^{\#}$ Indicates a significant difference from the T-25-treated group at $P<0.05$ (Duncan's multiple range tests)

concentrations between treatments. The T-25 group showed a significantly lower level of muscle SOD than the other groups.

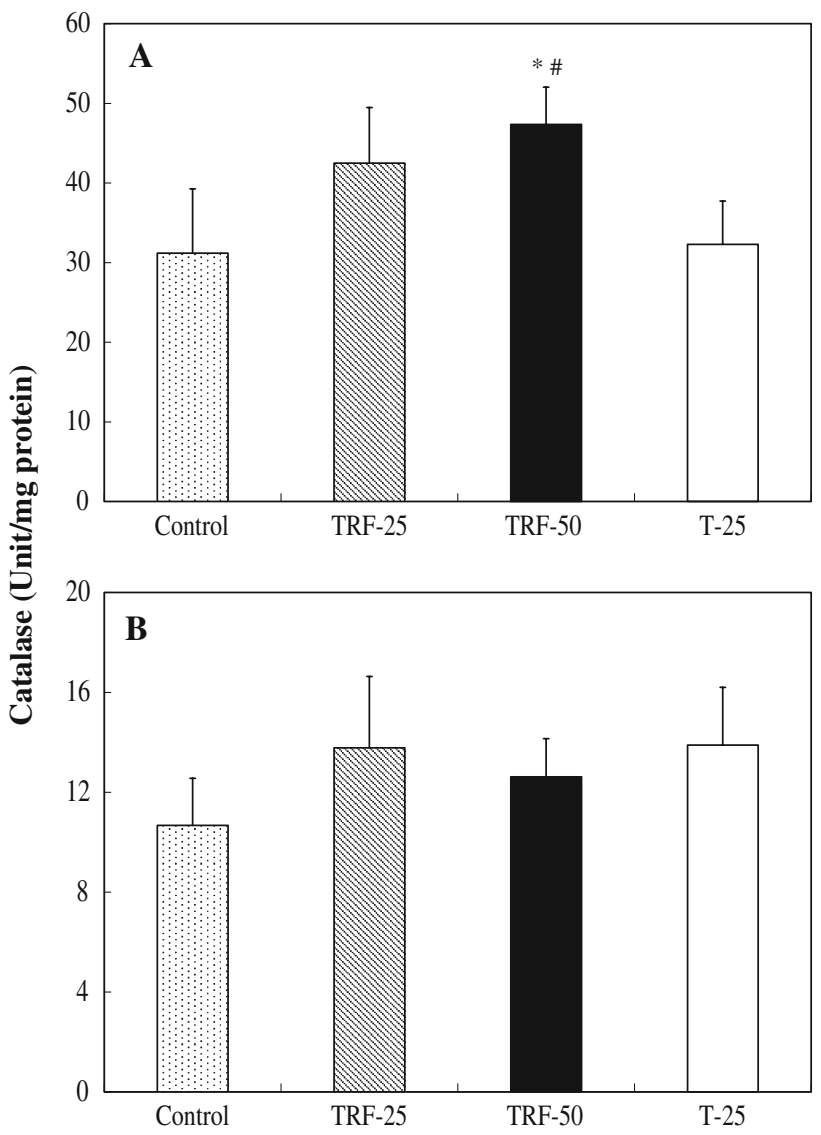

Fig. 7 Concentrations of catalase (CAT) after maximal swimming exercise in different tissues. a Liver and $\mathbf{b}$ muscle. Data are presented as mean $\pm \mathrm{SD}$ of ten rats per group. *Indicates a significant difference from the control group at $P<0.05$; ${ }^{\text {IIndicates a significant difference }}$ from the T-25-treated group at $P<0.05$ (Duncan's multiple range tests)

\section{Discussion}

The present study has demonstrated that TRF supplementation reduced oxidative stress from strenuous exercise. TRF administration significantly extended the swimming time of rats and displayed a lower level of blood lactate, and liver and muscle glycogen than other treatments. Furthermore, TRF can augment the level of antioxidant enzymes in the liver and effectively decrease the concentration of TBARS in plasma and liver, and protein carbonyl in liver and muscle of rats.

Physical exercise is known to improve health and prevent diseases. However, it was reported to cause oxidative stress (Alessio et al. 2000; Nieman et al. 2002), as demonstrated by (1) an increase in free radical generation in rat muscle and liver (Davies et al. 1982); (2) an increase in protein carbonyls and TBARS (Sen et al. 1997), and (3) a decrease in the level of antioxidants and antioxidant 


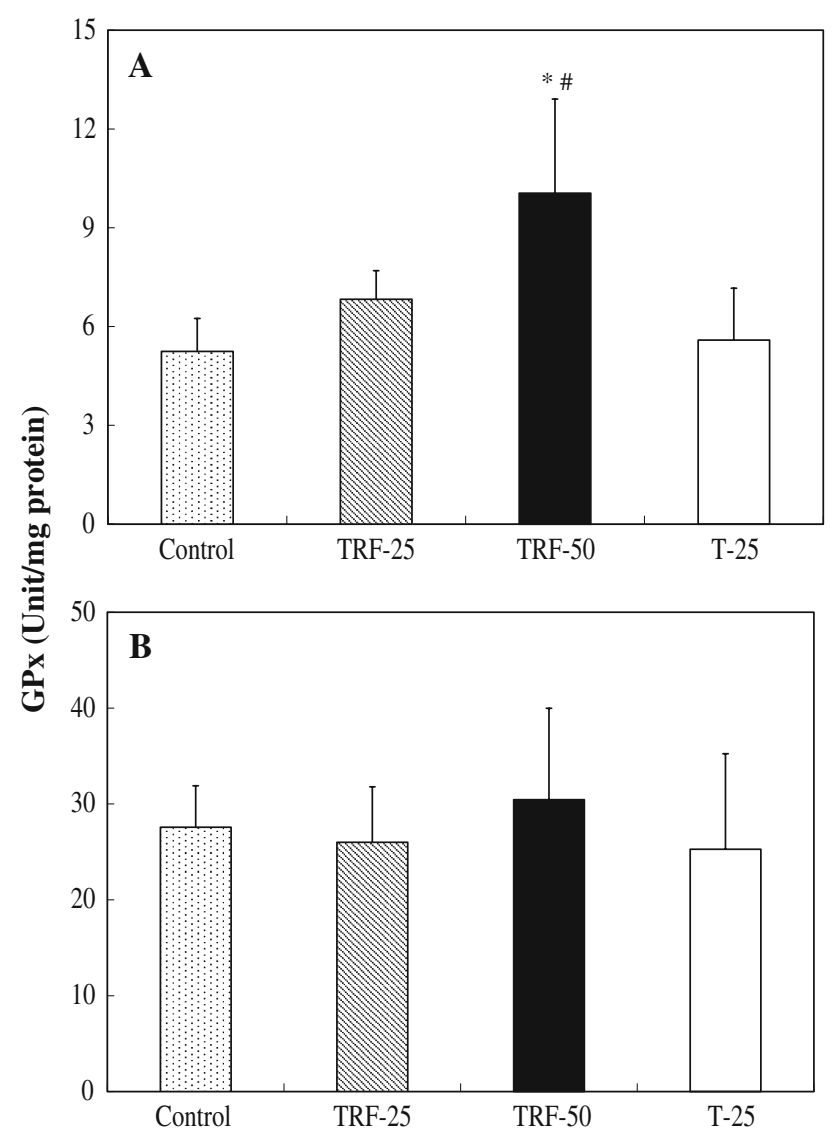

Fig. 8 Concentrations of glutathione peroxidase (GPx) after maximal swimming exercise in different tissues. a Liver and $\mathbf{b}$ muscle. Data are presented as mean $\pm \mathrm{SD}$ of ten rats per group. *Indicates a significant difference from the control group at $P<0.05$; "Indicates a significant difference from the T-25-treated group at $P<0.05$ (Duncan's multiple range tests)

enzymes in the heart (Reznick et al. 1982; Ciocoiu et al. 2007), blood, liver and muscle (Lew et al. 1985; Ji 1993), lung (Salminen et al. 1984), and brain (Somani et al. 1995). Therefore, antioxidant (e.g. vitamins $\mathrm{C}$ and E) supplementation is suggested to be a potential strategy to minimize oxidative stress-induced injury during exercise.

Compared with the control group, the swimming time of the TRF-treated rats was significantly longer than that of the T-25-treated group. As there were no differences in the body weight and food intake between the different treatments throughout the experimental period, this suggests that the increased exercise endurance capacity of TRF groups was not associated with the physical condition of the animals or due to the increase in the body fat composition. Under the present model system of study, T-25, a commonly used antioxidant, failed to demonstrate an increase in exercise endurance capacity. This implies that the performance-enhancing effect of TRF was mainly contributed by tocotrienols, but not by $\alpha$-tocopherol.

During exercise, organs such as liver and heart, and tissues such as skeletal muscle, help to remove lactate from the blood (Bonen 2000; Brooks 2000), but intense exercise can increase lactate production. Glycogen reserves, another fatigue factor, are source of energy in the liver and muscle; their reduction during exercise can cause insufficient energy supply or oxygen to the muscles thus inducing muscle fatigue. In this study, our results showed that oral administration of TRF can effectively attenuate the increase of blood lactate and maintain the glycogen level. TRF also preserved the liver and muscle glycogen more effectively than $\mathrm{T}$. Therefore, it is possible that the improvement of physiological function or metabolic control of lactate production and/or removal may have contributed to the enhanced swimming capacity of rats.

TAC indicates the cumulative effect of all antioxidants present in plasma and is used to evaluate a number of physiological conditions in human and animals (Ghiselli et al. 2000). It has been reported that exercise decreased plasma TAC in rats (Ficicilar et al. 2003). Compared with the control group, supplementation of TRF-25 and T-25 showed no significant increase in the plasma TAC level after strenuous exercise. Surprisingly, the exercise endurance capacity of TRF-25 was better than that of T-25. This suggests that the levels of glycogen and lactate in liver, muscle, and blood may have played an important role in improving the swimming performance of the TRF-treated rats. In addition to these two bio-indicators, the high level of TAC in plasma of the TRF-50 group would have further improved the endurance capacity.

The antioxidant defense systems of the living body consist of antioxidant enzymes (i.e. SOD, CAT and GPx) and antioxidant nutrients (e.g. vitamin C, vitamin E, polyphenols), which may be involved in reducing oxidative stress (Leibovitz et al. 1900; Zoppi et al. 2006; Ciocoiu et al. 2007; Wu and $\mathrm{Ng}$ 2007). As antioxidant enzymes play an important role in the protection against free radical damage, a decrease in the activities or expressions of these enzymes may predispose tissues to the free radical damage. Physical exercise is known to have differential effects on antioxidant enzymes (Salminen and Vihko 1983). In humans, exercise training was shown to increase activities of skeletal muscle SOD (Jenkins et al. 1984) and other protective enzymes in blood (Robertson et al. 1991). Long-term exercise training has been shown to increase the activities of SOD and CAT (Higuchi et al. 1985), and GPx (Ji 1993) in muscle. However, other studies reported that strenuous exercise causes a dramatic drop in hepatic antioxidant enzymes (Hong and Johnson 1995). Although inconsistent findings have been reported on the level of antioxidant enzymes, it appears that the variation of these enzymes is dependent not only on the type of tissues measured, but also on the mode and intensity of exercise.

Free radicals are produced by lipid peroxidation derived from oxygen, and the first line of defense against them is SOD. The increase in SOD in both liver and muscle would 
indicate an up-regulation of the defense mechanism to try to cope with an enhanced production of superoxide anion radicals. This in turn might help to down-regulate the production of lipid peroxides or oxidative stress. As shown in this study, the animals receiving TRF-50 appeared to have higher levels of SOD in liver and muscle, which were accompanied by significant decreases in lipid peroxidation. The increases in the level of antioxidant enzymes (i.e. SOD, CAT and GPx) in liver and muscle were found to be more pronounced in the TRF-treated animals than in the T-treated group, suggesting that TRF administration was able to up-regulate antioxidant enzymes to protect against oxidative stress-induced injury during exercise.

Protein carbonyl and TBARS, oxidative products of protein and lipid, respectively, are well known as useful markers for assessing oxidative stress in vivo (Hong and Johnson 1995; Sen et al. 1997; Bejma and Ji 1999). Studies have shown that physical exercise can result in an increase in oxidative stress in vivo (Ji 1999; Alessio et al. 2000; Ciocoiu et al. 2007), which is known to play an important role in the muscle fatigue or damage in single muscle fibers (Andrade et al. 1998). Oxidative damage of proteins is accompanied by an increased number of carbonyl residues after endurance exercise in rat skeletal muscles (Levine et al. 1990; Ji 1999). In this study, the TRF-treated rats tended to have lower levels of protein carbonyl in liver and muscle. Compared with other treatments, significant lower levels of protein carbonyl in the TRF-50-treated group were noted. TRF also significantly decreased the level of TBARS in plasma and liver. These results indicate that TRF may confer protection against oxidative stress-induced injury in animals, suggesting a possible beneficial effect of TRF supplementation on strenuous exercise.

In conclusion, this is the first study to demonstrate that TRF could enhance exercise endurance and possess protective effects against oxidative stress in rats undergoing strenuous exercise. Our study also revealed that TRF treatment elevates the levels of SOD, CAT and GPx, which are accompanied by corresponding decreases in protein carbonyl and TBARS levels, suggesting that TRF can prevent exercise-induced protein and lipid oxidation. In addition, TRF may also be involved in glycogen metabolism and the control of lactate production, and/or removal.

Acknowledgment The authors would like to thank Mr. David Ho (Carotech Ltd., Malaysia) for generously providing the tocotrienolrich fraction of palm oil for use in this study.

\section{References}

Abe T, Takiguchi Y, Tamura M, Shimura J, Yamazaki K (1995) Effect of vespa amino acid mixture (VAAM) isolated from hornet larval saliva and modified VMM nutrients on endurance exercise in swimming mice improvement in performance and changes of blood lactate and glucose. Jpn J Physiol Fitness Sports Med 44:225-238

Aikawa KM, Quintanilha AT, de Lumen BO, Brooks GA, Packer L (1984) Exercise endurance-training alters vitamin E tissue levels and red blood cell hemolysis in rodents. Biosci Rep 4:253-257

Alessio HM, Hagerman AE, Fulkerson BK, Ambrose J, Rice RE, Wiley RL (2000) Generation of reactive oxygen species after exhaustive aerobic and isometric exercise. Med Sci Sports Exerc 32:1576-1581

Andrade FH, Reid MB, Allen DG, Westerblad H (1998) Effect of hydrogen peroxide and dithiothreitol on contractile function of single skeletal muscle fibres from the mouse. J Physiol (Lond) 509:565-575

Ashton T, Rowlands CC, Jones E, Young IS, Jackson SK, Davies B et al (1998) Electron spin resonance spectroscopic detection of oxygen centred radicals in human serum following exhaustive exercise. Eur J Appl Physiol Occup Physiol 77:498-502

Beers RF Jr, Sizer IW (1952) A spectrophotometric method for measuring the breakdown of hydrogen peroxide by catalase. J Biol Chem 195:133-140

Bejma J, Ji LL (1999) Aging and acute exercise enhance free radical generation in rat skeletal muscle. J Appl Physiol 87:465-470

Bieri JG, Anderson AA (1960) Peroxidation of lipids in tissue homogenates as related to vitamin E. Arch Biochem Biophys 90:105-110

Bonen A (2000) Lactate transporters (MCT proteins) in heart and skeletal muscles. Med Sci Sports Exerc 32:778-789

Brooks GA (2000) Intra- and extra-cellular lactate shuttles. Med Sci Sports Exec 32:790-799

Caroll NV, Longley RW, Roe JH (1956) The determination of glycogen in liver and muscle by use of anthrone reagent. J Biol Chem 220:583-593

Chiaradia E, Avellini L, Rueca F, Spaterna A, Porciello F, Antonioni MT et al (1988) Physical exercise, oxidative stress and muscle damage in racehorses. Comp Biochem Physiol B 119:833-836

Ciocoiu M, Badescu M, Paduraru I (2007) Protecting antioxidative effects of vitamins $\mathrm{E}$ and $\mathrm{C}$ in experimental physical stress. J Physiol Biochem 63:187-194

Davies KJA, Quintanilha AT, Brooks GA, Packer L (1982) Free radicals and tissue damage produced by exercise. Biochem Biophys Res Commun 107:1198-1205

Ficicilar H, Zergeroglu AM, Tekin D, Eroz G (2003) The effects of acute exercise on plasma antioxidant status and platelet response. Thromb Res 111:267-271

Ghiselli A, Serafini M, Natella F, Scaccini C (2000) Total antioxidant capacity as a tool to assess redox status: critical view and experimental data. Free Rad Biol Med 29:1106-1114

Goh SH, Hew NF, Norhanom AW, Yadav M (1994) Inhibition of tumour promotion by various palm oil tocotrienols. Int J Cancer 57:529-531

Higuchi M, Cartier LJ, Chen M, Holloszy JO (1985) Superoxide dismutase and catalase in skeletal muscle: adaptive response to exercise. J Gerontol A Biol Sci Med Sci 40:281-286

Hong H, Johnson P (1995) Antioxidant enzyme activities and lipid peroxidation levels in exercised and hypertensive rat tissues. Int J Biochem Cell Biol 27:923-931

Jenkins RR, Friedland R, Howald H (1984) The relationship of oxygen uptake to superoxide dismutase and catalase activity in human skeletal muscle. Int J Sports Med 5:11-14

Ji LL (1993) Antioxidant enzyme response to exercise and aging. Med Sci Sports Exerc 25:225-231

Ji LL (1999) Antioxidants and oxidative stress in exercise. Proc Soc Exp Biol Med 222:283-292 
Kamat JP, Devasagayam TPA (1995) Tocotrienols from palm oil as potent inhibitors or lipid peroxidation and protein oxidation in rat brain mitochondria. Neurosci Lett 195:179-182

Kimura YM, Kubo M, Tani T, Arichi S, Okuda H (1981) Studies on Scutellariae radix IV: effects on lipid peroxidation in rat liver. Chem Pharm Bull 29:2610-2617

Kumar CT, Reddy VK, Prasad M, Thyagaraju K, Reddanna P (1992) Dietary supplementation of vitamin $\mathrm{E}$ protects heart tissue from exercise-induced oxidant stress. Mol Cell Biochem 111:109-115

Leibovitz BE, Hu ML, Tappel AL (1990) Dietary supplements of vitamin E, beta carotene, coenzyme Q10 and selenium protect tissues against lipid peroxidation in rat tissue slices. Lipids 25:125-129

Levine RL, Galand D, Oliver CN (1990) Determination of carbonyl content in oxidatively modified proteins. Methods Enzymol 186:464-478

Lew H, Pyke S, Quintanilha A (1985) Changes in the glutathione status of plasma, liver and muscle following exhaustive exercise in rats. FEBS Lett 185:262-266

Maniam S, Mohamed N, Shuid AN, Soelaiman IN (2008) Palm tocotrienol exerted better antioxidant activities in bone than alphatocopherol. Basic Clin Pharmacol Toxicol 103:55-60

Meydani M, Evans WJ, Handelman G, Biddle L, Fielding RA, Meydani SN et al (1993) Protective effect of vitamin E on exercise-induced oxidative damage in young and older adults. Am J Physiol 264:R992-R998

Minhajuddin M, Beg ZH, Iqbal J (2005) Hypolipidemic and antioxidant properties of tocotrienol rich fraction isolated from rice bran oil in experimentally induced hyperlipidemic rats. Food Chem Toxicol 43:747-753

Nesaretnam K, Devasagayam TPA, Singh BB, Basiron Y (1993) Influence of palm oil or its tocotrienol-rich fraction on the lipid peroxidation potential of rat liver mitochondria and microsomes. Biochem Mol Biol Inter 30:159-167

Nieman DC, Henson D, McAnulty SR, McAnulty L, Swick NS, Utter $A C$ et al (2002) Influence of vitamin C supplementation on oxidative and immune changes after an ultra-marathon. J Appl Physiol 92:1970-1977

Novelli GP, Bracciotti G, Falsini S (1990) Spin-trappers and vitamin E prolong endurance to muscle fatigue in mice. Free Rad Biol Med 8:9-13

Osakada F, Hashino A, Kume T, Katsuki H, Kaneko S, Akaike A (2004) $\alpha$-Tocotrienol provides the most potent neuroprotection among vitamin $E$ analogs on cultured striatal neurons. Neuropharmacol 47:904-915

Polidori MC, Mecocci P, Cherubin A, Senin U (2000) Physical activity and oxidative stress during aging. Int J Sports Med 21:154-157

Qureshi AA, Bradlow BA, Brace L, Manganello J, Peterson DM, Pearce BC et al (1995) Response of hypercholesterolemic subjects to administration of tocotrienols. Lipids 30:1171-1177

Re R, Pellegrini N, Proteggente A, Pannala A, Yang M, Rice-Evans C (1999) Antioxidant activity applying an improved ABTS radical cation decolorization assay. Free Rad Biol Med 26:1231-1237
Reznick AZ, Steinhagen-Thiessen E, Gershon D (1982) The effect of exercise on enzyme activities in cardiac muscles of mice of various ages. Biochem Med 28:347-352

Robertson JD, Maughan RJ, Duthie GG, Morrice PC (1991) Increased blood antioxidant system of runners in response to training load. Clin Sci (Colch) 80:1333-1336

Rossi AL, Blostein-Fujii A, DiSilvesto RA (2000) Soy beverage consumption by young men: increased plasma total antioxidant status and decreased acute, exercise-induced muscle damage. J Nutr Func Med Foods 3:279-291

Rotruck JT, Pope AL, Ganther HE, Swanson AB, Hafeman DG, Hoekstra WG (1973) Selenium: biochemical role as a component of glutathione peroxidase. Science 179:588-590

Salminen A, Vihko V (1983) Endurance training reduces the susceptibility of mouse skeletal muscle to lipid peroxidation in vitro. Acta Physiol Scand 177:105-110

Salminen A, Kainulainen H, Vihko V (1984) Endurance training and antioxidants of lung. Experientia 40:822-823

Sen CK, Atalay M, Agren J, Laaksonnen DE, Hanninen O (1997) Fish oil and vitamin E supplementation in oxidative stress at rest and after physical exercise. J Appl Physiol 83:189-195

Sen CK, Khanna S, Roy S, Packer L (2000) Molecular basis of vitamin E action. Tocotrienol potently inhibits glutamate-induced pp60(c-Src) kinase activation and death of HT4 neuronal cells. J Biol Chem 275:13049-13055

Serbinova B, Kagan Y, Han D, Packer L (1991) Free radical recycling and intramembrane mobility in the antioxidant properties of alpha-tocopherol and alpha-tocotrienol. Free Rad Biol Med 10:263-275

Somani SM, Ravi R, Rybak LP (1995) Effect of exercise training on antioxidant system in brain regions of rat. Pharmacol Biochem Behav 50:635-639

Sun M, Zigman S (1978) An improved spectrophotometric assay for superoxide dismutase based on epinephrine autoxidation. Anal Biochem 90:81-89

Takahashi K, Loo G (2004) Disruption of mitochondria during tocotrienol-induced apoptosis in MDA-MB-231 human breast cancer cells. Biochem Pharmacol 67:315-324

Tiidus PM, Behrens WA, Madere R, Kim JJ, Houston ME (1993) Effects of vitamin $\mathrm{E}$ status and exercise training on tissue lipid peroxidation based on two methods of assessment. Nutr Res 13:219-224

Wu SJ, Ng LT (2007) Antioxidant and antihepatoma activities of palm oil extract. J Food Lipids 14:122-137

Wu SJ, Liu PL, Ng LT (2008) Tocotrienol-rich fraction of palm oil exhibits anti-inflammatory property by suppressing the expression of inflammatory mediators in human monocytic cells. Mol Nutr Food Res 52:921-929

Zoppi CC, Hohl R, Silva FC, Lazarim LF, Neto JM, Stancanneli M et al (2006) Vitamin $\mathrm{C}$ and $\mathrm{E}$ supplementation effects in professional soccer players under regular training. J Int Soc Sports Nutr $3: 37-44$ 